\title{
Estimação de teores de componentes fibrosos em alimentos para ruminantes em sacos de diferentes tecidos ${ }^{1}$
}

\author{
André Oliveira Casali ${ }^{2}$, Edenio Detmann ${ }^{3}$, Sebastião de Campos Valadares Filho ${ }^{3}$, José Carlos \\ Pereira $^{3}$, Maura da Cunha ${ }^{4}$, Kelly da Silva Coutinho Detmann ${ }^{5}$, Mário Fonseca Paulino ${ }^{3}$
}

1 Trabalho parcialmente financiado pela FAPEMIG (Programa Pesquisador Mineiro).

2 Programa de Pós-Graduação em Zootecnia, Universidade Federal de Viçosa, Viçosa-MG, CEP: 36571-000.

${ }^{3}$ Departamento de Zootecnia, Universidade Federal de Viçosa, Viçosa-MG. Pesquisador do CNPq.

${ }^{4}$ Laboratório de Biologia Celular e Tecidual, Universidade Estadual do Norte Fluminense, Campos dos Goytacazes-RJ.

${ }^{5}$ Departamento de Biologia Vegetal, Universidade Federal de Viçosa, Viçosa-MG.

RESUMO - Objetivou-se avaliar os teores de fibra em detergente neutro indigestível (FDNi) obtidos por procedimento in situ e a perda de partículas fibrosas em meio aquoso de alguns alimentos para ruminantes, utilizando sacos de diferentes tecidos. Observou-se, concomitantemente, a estrutura física dos tecidos utilizados. Os alimentos avaliados foram: farelo de trigo (FT), casca de soja (CS), silagem de milho (SM) e feno de capim-braquiária (FB); e os tecidos: náilon (50 $\mu$ m); F57 $\left(\right.$ Ankom $\left.{ }^{\circledR}\right)$; e tecido não-tecido (TNT $-100 \mathrm{~g} / \mathrm{m}^{2}$ ). Os alimentos foram moídos (1 mm) e acondicionados em sacos de $4 \times 5 \mathrm{~cm}$ (seis amostras de cada alimento/tecido), obedecendo à relação de $20 \mathrm{mg}$ de matéria seca/cm² de superfície. Os sacos foram incubados por 144 horas no rúmen de uma vaca alimentada com silagem de milho (70\%) e concentrado (30\%) e, posteriormente, foram retirados, lavados com água corrente até o total clareamento desta, e tratados com detergente neutro (o resíduo foi considerado FDNi). Verificou-se similaridade entre os teores de FDNi obtidos com TNT e F57, que foram superiores aos obtidos com náilon para os alimentos farelo de trigo, casca de soja e silagem de milho. Para as amostras de $\mathrm{PB}$, os teores diferiram entre todos os tecidos: foram maiores quando estimados utilizando-se F57, menores quando utilizado náilon e intermediários quando utilizado TNT. A perda de partículas fibrosas em meio aquoso foi avaliada por meio de lavagem em água $\left(39^{\circ} \mathrm{C}\right)$ dos sacos contendo os alimentos (10 amostras/tecido). Houve perda de partículas fibrosas quando empregado o náilon como tecido para avaliação das amostras, o que justifica os menores teores de FDNi obtidos com este tecido. A perda de partículas para o náilon está relacionada à estrutura do tecido, uma vez que, em análise por microscopia eletrônica de varredura, não foram observados danos nos tecidos durante os processos de incubação e extração com detergente.

Palavras-chave: F57, náilon, sistema Ankom, tecido não-tecido

\section{Estimation of fibrous compounds contents in ruminant feeds with bags made from different textiles}

\begin{abstract}
The aim of this work was to evaluate the contents of in situ indigestible neutral detergent fiber (iNDF) and the fibrous particles lost in aqueous environment in some ruminant feeds by using bags made with different textiles The physical structure of the textiles was also observed. Wheat bran (WB), soybean hulls (SH), corn silage (CS), and signal grass hay (SGH) samples were used. The bags used for rumen incubation were made of nylon (50 $\mu \mathrm{m})$; F57 (Ankom $\left.{ }^{\circledR}\right)$; and non-woven textile $\left(\mathrm{NWT}-100 \mathrm{~g} / \mathrm{m}^{2}\right)$. The feed samples were ground $(1 \mathrm{~mm})$ and conditioned in bags $(4 \times 5 \mathrm{~cm})(\mathrm{six}$ bags of each feedstuff/textile), in a ratio of $20 \mathrm{mg}$ of dry matter $/ \mathrm{cm}^{2}$ of surface. The bags were incubated in the rumen of a cow fed with corn silage (70\%) and concentrate (30\%) for 144 hours. After that, the bags were removed, cleaned with running water and treated with neutral detergent. The residue was assumed as iNDF. The iNDF contents in WB, SH and CS were similar for F57 and NWT, but lower values were obtained when nylon was used For the SGH samples, all textiles produced different results, and the lowest contents were obtained with nylon. The fibrous particle losses in the aqueous environment were evaluated by cleaning the bags in warm running water $\left(39^{\circ} \mathrm{C}\right)(10 \mathrm{bags} / \mathrm{textile})$. The loss of fibrous particles was significant for nylon. This loss was considered the cause of lower iNDF contents obtained by using nylon textile, since the microscopic evaluation did not show the occurrence of ruptures during incubation or neutral detergent extraction.
\end{abstract}

Key Words: Ankom system, F57, non-woven, nylon, textile 


\section{Introdução}

A recuperação de frações indigestíveis do alimento constitui a base para a utilização de indicadores internos em estudos de digestibilidade (Van Soest, 1994). Além de representar a fração fibrosa insolúvel indigestível dos alimentos, a fibra em detergente neutro indigestível (FDNi) vem sendo utilizada como indicador interno, estimada com base em procedimentos de incubação ruminal in situ ou in vitro em tempos superiores a 120 horas (Detmann et al., 2004).

Contudo, incubações in vitro podem apresentar como inconveniente a aderência de partículas à parede do tubo, evitando o contato destas partículas com o inóculo ruminal e acarretando aumento irreal do resíduo pósincubação (Freitas et al., 2002). Este relato confirma os resultados obtidos por Huhtanen et al. (1994) de que a digestibilidade da matéria seca in vivo foi predita com maior exatidão quando avaliados os resíduos indigestíveis da fibra obtidos por procedimento in situ, em comparação às estimativas produzidas por procedimento in vitro.

Desta forma, os procedimentos in situ parecem ser capazes de produzir resultados mais verossímeis das concentrações de indicadores internos em alimentos e fezes. Contudo, divergências ainda são observadas quanto à forma de implementação, à adequação e condução de métodos in situ.

O náilon tem sido empregado como recipiente padrão (sacos) em procedimentos de incubação in situ (Nocek, 1997). Entretanto, resultados controversos têm sido relatados quanto à eficiência de utilização deste tipo de tecido no processo de estimação de resíduos indigestíveis. Como exemplo, Piaggio et al. (1991) avaliaram a concentração de resíduos fibrosos indigestíveis obtida por incubação in situ (240 horas) e verificaram recuperação fecal incompleta, que atribuíram à perda de partículas pelos poros dos sacos de náilon (50 $\mu \mathrm{m})$.

O surgimento do sistema Ankom ${ }^{\circledR}$ para avaliação do teor de fibra proporcionou maior praticidade e precisão para avaliação dos resíduos fibrosos indigestíveis, uma vez que o recipiente utilizado para a incubação in situ pode ser empregado simultaneamente para avaliação da fibra residual, sem a necessidade de transferência de amostra dos sacos para as vidrarias utilizadas em procedimentos rotineiros de avaliação de fibra em laboratório. Os sacos associados ao sistema Ankom ${ }^{\circledR}$ são compostos por fibra sintética insolúvel nos meios ácido e neutro e denominados F57 (Ankom ${ }^{\circledR}$ ).

Embora a aplicação do F57 para avaliação do teor de fibra em alimentos apresente perspectivas favoráveis
(Berchielli et al., 2001), o custo associado a esse material pode inviabilizar sua aplicação rotineira em análise de alimentos. Recentemente, têm-se buscado alternativas a este material na utilização do sistema Ankom ${ }^{\circledR}$ de análise de fibra, entre essas, o tecido não-tecido (TNT), com gramatura $100 \mathrm{~g} / \mathrm{m}^{2}$.

Contudo, diante da perspectiva de utilização de vários tecidos para realização de procedimentos in situ de estimação das concentrações de resíduos indigestíveis, gera-se demanda premente para avaliação desses materiais quanto a aspectos primários de interferência na exatidão e precisão dos resultados, e a aspectos secundários, que envolvem custos e praticidade operacional.

Desta forma, objetivou-se observar a integridade física pós-incubação e pós-extração com detergente e avaliar as perdas de partículas e as estimativas dos teores de FDNi de alguns alimentos para ruminantes obtidas em procedimento in situ utilizando-se sacos confeccionados com os tecidos náilon ( $50 \mu \mathrm{m}), \mathrm{F} 57$ (Ankom ${ }^{\circledR}$ ) e tecido não-tecido (TNT $\left.-100 \mathrm{~g} / \mathrm{m}^{2}\right)$.

\section{Material e Métodos}

Este experimento foi conduzido nas dependências dos Laboratórios de Animais e de Nutrição Animal do Departamento de Zootecnia da Universidade Federal de Viçosa, Viçosa, Minas Gerais.

Foram utilizadas amostras de farelo de trigo, casca de soja, silagem de milho e feno de capim-braquiária (Brachiaria decumbens Stapf.), todas coletadas no município de Viçosa, Minas Gerais. A escolha destes alimentos visou propiciar a avaliação de concentrados ricos em fibra e volumosos de média (feno de capimbraquiária) e alta qualidade (silagem de milho). As amostras de silagem de milho foram pré-secas em estufa com ventilação forçada ( $60^{\circ} \mathrm{C} / 72$ horas) e, posteriormente, em conjunto com as demais amostras, processadas em moinho de facas com peneira com malha de $1 \mathrm{~mm}$.

As amostras foram analisadas quanto aos teores de matéria seca (MS), proteína bruta (PB), fibra em detergente ácido (FDA) e lignina $\left(\mathrm{H}_{2} \mathrm{SO}_{4} 72 \% \mathrm{p} / \mathrm{p}\right)$, segundo métodos descritos por Silva \& Queiroz (2002). As avaliações das concentrações de fibra em detergente neutro (FDN) seguiram os protocolos sugeridos por Mertens (2002), com uso de amilase termoestável (Termamyl 120 L), sem o uso de sulfito de sódio. Omitiu-se, no entanto, a correção quanto às cinzas insolúveis em detergente neutro (CIDN) (Tabela 1). Todas as demais análises de FDN realizadas neste trabalho seguiram esta padronização. 
Tabela 1 - Composição química dos alimentos

\begin{tabular}{lccrr}
\hline & \multicolumn{3}{c}{ Alimento } \\
\cline { 2 - 5 } Item $^{1}$ & Farelo de trigo & Casca de soja & Silagem de milho & Feno de braquiária \\
\hline MS $^{2}$ & 86,53 & 90,30 & 33,97 & 89,92 \\
PB $^{3}$ & 15,30 & 11,1 & 6,70 & 6,95 \\
FDN $^{3}$ & 45,64 & 81,21 & 47,64 & 82,49 \\
FDA $^{3}$ & 12,26 & 62,37 & 28,44 & 35,83 \\
Lignina $^{3}$ & 3,51 & 4,06 & 7,19 & 8,74 \\
\hline
\end{tabular}

${ }_{1}^{1} \mathrm{MS}$ = matéria seca; $\mathrm{PB}$ = proteína bruta; FDN = fibra em detergente neutro; FDA = fibra em detergente ácido.

$2 \%$ da matéria natural.

$3 \%$ da matéria seca.

Para avaliação dos teores de fibra em detergente neutro indigestível (FDNi), os alimentos foram acondicionados em sacos confeccionados com os tecidos: náilon, com porosidade de $50 \mu \mathrm{m}$; F57 (Ankom ${ }^{\circledR}$ ); e tecido não-tecido (TNT) $\left(100 \mathrm{~g} / \mathrm{m}^{2}\right)$. Foram utilizadas seis repetições de cada alimento para cada material.

Os sacos de náilon e TNT foram confeccionados com as dimensões $4 \times 5 \mathrm{~cm}$. As amostras foram acondicionadas, em todos os sacos, seguindo-se a relação de 20 mg de MS por centímetro quadrado de superfície (Nocek, 1997).

Posteriormente, os sacos foram incubados por 144 horas (Detmann et al., 2001) no rúmen de uma vaca mestiça (Holandês $\times$ Zebu) alimentada com dieta contendo, com base na MS, 70\% de silagem de milho e 30\% de concentrado (composto por fubá de milho, farelo de soja e mistura mineral). Após o período de incubação, os sacos foram retirados, lavados com água corrente até o total clareamento desta, submetidos à extração com detergente neutro (Mertens, 2002), em equipamento analisador de fibra Ankom ${ }^{200 ®}$, e lavados com água quente e acetona. Após esse tratamento, os sacos foram secos em estufa de ventilação forçada $\left(60^{\circ} \mathrm{C} / 72\right.$ horas) e em estufa nãoventilada $\left(105^{\circ} \mathrm{C} / 45\right.$ minutos), acondicionados em dessecador e pesados. Os sacos de todos os tecidos foram lavados com detergente neutro e secos de forma similar ao acima descrito anteriormente à incubação para que se obtivessem as taras.

Os teores de FDNi obtidos com os sacos foram avaliados por meio de análise de variância, de forma independente para cada alimento, segundo delineamento inteiramente casualizado, considerando três materiais para confecção dos sacos e seis repetições por material. As médias foram comparadas por intermédio do teste Scheffé $(\alpha=0,05)$ (Steel et al., 1997).

Para a observação da integridade dos tecidos após as etapas analíticas, foram avaliados, concomitantemente aos procedimentos de incubação, três sacos "em branco" para cada material. O primeiro saco foi submetido somente aos procedimentos para obtenção das taras. O segundo saco, por sua vez, foi submetido também aos procedimentos de incubação e lavagem e o terceiro saco, a todo o processo analítico, inclusive à extração com detergente. Posteriormente, amostras do tecido de cada saco foram submetidas à avaliação por microscopia eletrônica de varredura (Silveira, 1998).

Após secagem $\left(105^{\circ} \mathrm{C} / 45 \mathrm{~min}\right)$, fragmentos dos tecidos de todos os sacos foram fixados com cola carbono em suportes metálicos e cobertos com uma camada de ouro (20 nm), sendo então avaliados em aumentos de 30, 100 e 200x em microscópio eletrônico de varredura (DSEM 962, Zeiss Co.). Todos os procedimentos de microscopia foram realizados no Laboratório de Biologia Celular e Tecidual (LBCT) do Centro de Biociências e Biotecnologia (CBB) da Universidade Estadual do Norte Fluminense (UENF), em Campos dos Goytacazes, Rio de Janeiro.

Um segundo procedimento de avaliação dos tecidos foi conduzido visando à avaliação das perdas de partículas fibrosas insolúveis nos alimentos.

Trinta amostras de cada alimento foram acondicionadas em sacos dos diferentes tecidos (10 amostras/tecido), obedecendo à mesma relação descrita anteriormente. Os sacos foram então lavados em água morna (aproximadamente $39^{\circ} \mathrm{C}$ ) até o total clareamento desta, e tratados com detergente neutro (Mertens, 2002), empregando-se equipamento Ankom ${ }^{200}{ }_{\circledR}$ para avaliação de fibras, segundo procedimentos descritos anteriormente.

Paralelamente, cinco amostras de cada alimento foram quantificadas quanto ao teor de FDN empregando-se sistema reboiler e cadinhos filtrantes (porosidade grossa), segundo o método oficial descrito pela AOAC International (Mertens, 2002), segundo as padronizações descritas anteriormente.

Para os teores de FDN obtidos pelos diferentes tecidos, foram construídos intervalos de confiança $(1-\alpha=0,95)$ (Steel et al., 1997) e, quando a média dos teores de FDN obtida via método AOAC esteve incluída nos respectivos 
intervalos de confiança, concluiu-se pela ausência de perdas significativas de partículas fibrosas pelo material $(\mathrm{P}>0,05)$. Em caso contrário, inferiu-se que perdas significativas foram observadas $(\mathrm{P}<0,05)$.

Todos os procedimentos estatísticos foram realizados por intermédio do programa Statistical Analisys System (Littell et al., 1991).

\section{Resultados e Discussão}

O teores de FDNi de farelo de trigo, casca de soja e silagem de milho (Tabela 2) obtidos com TNT e F57 foram superiores $(\mathrm{P}>0,05)$ aos obtidos com náilon $(\mathrm{P}<0,05)$.

Comportamento similar foi também observado por Nunes et al. (2005), ao compararem os teores de FDN e FDA em amostras de alimentos obtidas por intermédio de sacos de TNT e F57. Esses autores não observaram diferenças entre tecidos, o que indica a possibilidade do uso do TNT como material alternativo para análise de fibra.

Por outro lado, os teores de FDNi do feno de capimbraquiária diferiram entre todos os tecidos $(\mathrm{P}<0,05)$ : os maiores valores foram obtidos com o F57 e os menores com o náilon, enquanto valores intermediários foram obtidos com o TNT (Tabela 2). No entanto, apesar da diferença significativa, verificou-se maior proximidade entre os

Tabela 2 - Teores de fibra em detergente neutro indigestível (\% da matéria seca) obtidos com sacos confeccionados com diferentes tecidos

\begin{tabular}{lrrrrr}
\hline \multirow{2}{*}{ Alimento } & \multicolumn{3}{c}{ Tecido $^{1}$} & \\
\cline { 2 - 4 } & TN T & \multicolumn{1}{c}{ F57 } & Náilon & \multirow{2}{*}{ Valor-P2 } & CV (\%) \\
\hline Farelo de trigo & $14,20 \mathrm{a}$ & $14,43 \mathrm{a}$ & $10,41 \mathrm{~b}$ & $<0,0001$ & 6,3 \\
Casca de soja & $5,58 \mathrm{a}$ & $7,06 \mathrm{a}$ & $2,09 \mathrm{~b}$ & 0,0028 & 34,4 \\
Silagem de milho & $25,34 \mathrm{a}$ & $25,37 \mathrm{a}$ & $15,76 \mathrm{~b}$ & $<0,0001$ & 10,2 \\
Feno de braquiária & 33,59b & $36,70 \mathrm{a}$ & $26,35 \mathrm{c}$ & $<0,0001$ & 4,6 \\
\hline
\end{tabular}

${ }^{1}$ Médias na linha seguidas por letras diferentes são diferentes pelo teste Scheffé $(\mathrm{P}<0,05)$.

2 Níveis descritivos de probabilidade para o erro tipo I associados à hipótese de nulidade referente à similaridade entre tecidos.

Tabela 3 - Erros-padrão da média dos teores de fibra em detergente neutro indigestível obtidos com sacos confeccionados com diferentes tecidos

\begin{tabular}{lccc}
\hline & \multicolumn{3}{c}{ Tecido } \\
\cline { 2 - 4 } Alimento & T N T & F57 & Náilon \\
\hline Farelo de trigo & 1,007 & 0,902 & 0,428 \\
Casca de soja & 1,792 & 2,391 & 0,083 \\
Silagem de milho & 3,511 & 1,592 & 0,677 \\
Feno de braquiária & 1,679 & 1,289 & 1,437 \\
\hline
\end{tabular}

valores fornecidos por F57 (36,70\%) e TNT (33,59\%), em comparação ao fornecido pelo náilon (26,35\%), o que corrobora a similaridade entre estes tecidos para o farelo de trigo, a casca de soja e a silagem de milho.

Em avaliação dos erros-padrão, os resultados obtidos com os tecidos TNT e F57 foram similares em precisão experimental, contudo foram menos precisos que os obtidos com o náilon (Tabela 3).

Embora a estimação dos teores de FDNi seja rotineiramente empregada em experimentos de digestibilidade e consumo a pasto em ruminantes (Detmann et al., 2001), a elevada variabilidade entre procedimentos laboratoriais, associada à natureza químico-biológica heterogênea da FDN, não permite a fixação de um padrão analítico capaz de aferir a exatidão das estimativas obtidas. Desta forma, a comparação direta entre estimativas não permite, de forma concreta, afirmar sobre a veracidade dos resultados obtidos, o que limita as inferências à comparação em relação à precisão dos métodos.

Diversos autores (Hvelplund \& Weisbjerg, 2000; Berchielli et al., 2001) têm apontado a perda de partículas como o principal fator de comprometimento sobre a exatidão de procedimentos de avaliação de alimentos in situ. Essa perda pode conduzir à obtenção de valores superestimados de digestibilidade, visto que a fração perdida freqüentemente é associada ou confundida com a fração da MS rapidamente degradável e prontamente solúvel no ambiente ruminal.

Neste contexto, realizou-se procedimento secundário de avaliação da eficiência dos tecidos por meio da submissão dos sacos contendo os alimentos à lavagem em água com temperatura equivalente à observada no conteúdo ruminal $\left(39^{\circ} \mathrm{C}\right)$. Pressupondo que a FDN é completamente insolúvel em água (Van Soest, 1994), esperar-se-ia similaridade entre os teores estimados pelos diferentes tecidos com aqueles obtidos via cadinhos filtrantes, por intermédio do método oficial de análise (Mertens, 2002), caso não ocorressem perdas de partículas.

Embora se entenda que a avaliação dos tecidos por esse procedimento não permita simular totalmente os eventos que ocorrem durante o processo de incubação ruminal, pressupôs-se que a avaliação de perda de partículas da fração fibrosa insolúvel constituísse indicativo indireto da exatidão das estimativas de FDNi obtidas.

Caso o teor de fibra em detergente neutro (Tabela 4) obtido pelo método padrão oficial (Mertens, 2002) esteja contido no intervalo de confiança gerado para o teor médio obtido com os diferentes tecidos, pode-se inferir sobre a similaridade entre teores $(\mathrm{P}>0,05)$ e, conseqüentemente, concluir que a perda de partículas não é significativa. 
Neste contexto, verificou-se similaridade $(\mathrm{P}>0,05)$ entre os valores obtidos com o F57 e aqueles obtidos via método convencional (Mertens, 2002) para todos os alimentos avaliados (Tabela 4). Comportamento similar ao F57 foi verificado para o TNT com os alimentos farelo de trigo, feno de capim-braquiária e casca de soja. No entanto, divergência entre as estimativas foi observada para os valores obtidos para a silagem de milho, embora se tenha verificado elevada proximidade entre a média dada pelo método oficial (Mertens, 2002) e o limite superior do intervalo de confiança (Tabela 4).

Por outro lado, para o náilon, verificaram-se menores teores de FDN $(\mathrm{P}<0,05)$ em comparação àqueles fornecidos pelo método oficial (Mertens, 2002), o que indica perdas significativas de partículas de fibra insolúvel em meio aquoso $(\mathrm{P}<0,05)$, como o ambiente ruminal. Este comportamento parece justificar os menores teores de FDNi obtidos com este tecido (Tabela 2), que poderiam ser então atribuídos à perda de partículas, e não à maior amplitude de degradação.

Em trabalho visando avaliar a substituição do F57 por sacos de náilon com porosidade de $50 \mu \mathrm{m}$ em análises de fibra insolúvel, Berchielli et al. (2001) encontraram resultados insatisfatórios para amostras de fezes bovinas, que foram atribuídos à perda de amostra pelos poros do saco de náilon durante a extração com detergente. Desta forma, a porosidade pode ser considerada o principal fator que limita a utilização do náilon nos procedimentos para a análise de fibra e, conseqüentemente, de fibra indigestível.

Segundo Nocek (1997), a porosidade apropriada de um saco constitui ajuste entre limitar o influxo de conteúdo ruminal, não associado ao alimento avaliado, permitindo-se, no entanto, o influxo de populações microbianas para degradação, enquanto, ao mesmo tempo, limita-se a saída de partículas alimentares não-degradadas.

Apesar da evidência de perda de partículas quando se utiliza o náilon para análise de FDN e FDNi, este tecido manteve após incubação (Figura 1b) e tratamento com detergente neutro (Figura 1c) a mesma integridade física pré-incubação (Figura 1a), portanto, a perda de partículas observada neste tecido está relacionada à estrutura do tecido e não a possíveis danos durante os processos de incubação e extração com detergente, uma vez que o tecido se manteve visualmente íntegro durante todo o processo de quantificação dos teores de FDNi (Figura 1). Resultados similares quanto à integridade de tecido foram também verificados para o F57 e o TNT (Figuras 2 e 3).

Huhtanen et al. (1994), ao compararem a digestibilidade da MS em bovinos predita utilizando a FDNi estimada por procedimentos in situ com sacos de náilon com malha de porosidade 6 e $41 \mu \mathrm{m}$, verificaram que as estimativas mais acuradas foram obtidas com a menor porosidade. Segundo esses autores, a menor exatidão associada à malha com $41 \mu \mathrm{m}$ foi atribuída à maior perda de partículas nãodegradadas.

Tabela 4 - Teores de fibra em detergente neutro (\% da matéria seca) obtidos com sacos de diferentes tecidos

\begin{tabular}{|c|c|c|c|c|c|}
\hline Método & Item & \multicolumn{4}{|c|}{ Alimento } \\
\hline Convencional $^{1}$ & Média (\%) & 45,64 & 47,64 & 82,49 & 81,21 \\
\hline \multirow[t]{3}{*}{ F57 } & Média (\%) & 47,18 & 49,00 & 82,27 & 82,22 \\
\hline & $\mathrm{s}$ & 1,867 & 1,596 & 0,671 & 2,289 \\
\hline & LI & 45,46 & 47,53 & 81,79 & 80,58 \\
\hline \multirow[t]{5}{*}{ TNT } & Média (\%) & 45,50 & 45,74 & 81,89 & 80,77 \\
\hline & $\mathrm{s}$ & 3,010 & 1,161 & 0,878 & 1,796 \\
\hline & LI & 43,35 & 44,85 & 81,15 & 79,48 \\
\hline & LS & 47,66 & 46,63 & 82,62 & 82,05 \\
\hline & $\operatorname{PPF}(\%)^{2,3}$ & - & 3,99 & - & - \\
\hline \multirow{2}{*}{ Náilon } & LS & 44,74 & 43,96 & 81,44 & 76,69 \\
\hline & PPF $(\%)^{2,3}$ & 5,19 & 11,99 & 1,87 & 6,10 \\
\hline
\end{tabular}

${ }^{1}$ Estimativas obtidas via método convencional (Mertens, 2002) com uso de cadinhos filtrantes.

2 PPF = perda de partículas fibrosas (Valor estimado com base na diferença entre o teor de FDN obtido com a avaliação via tecido e via método convencional).

${ }^{3}$ A perda de partículas fibrosas foi estimada somente para os casos em que esta foi considerada significativa $(\mathrm{P}<0,05)$. 
(a)

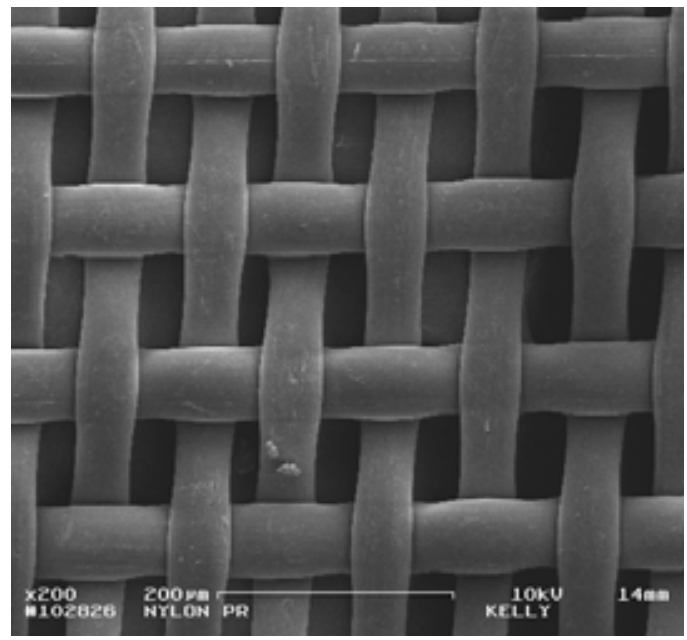

(b)

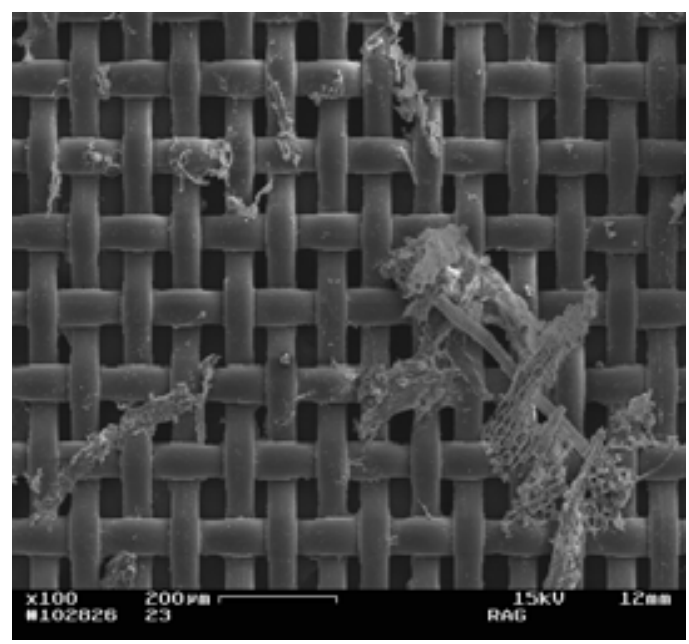

(c)

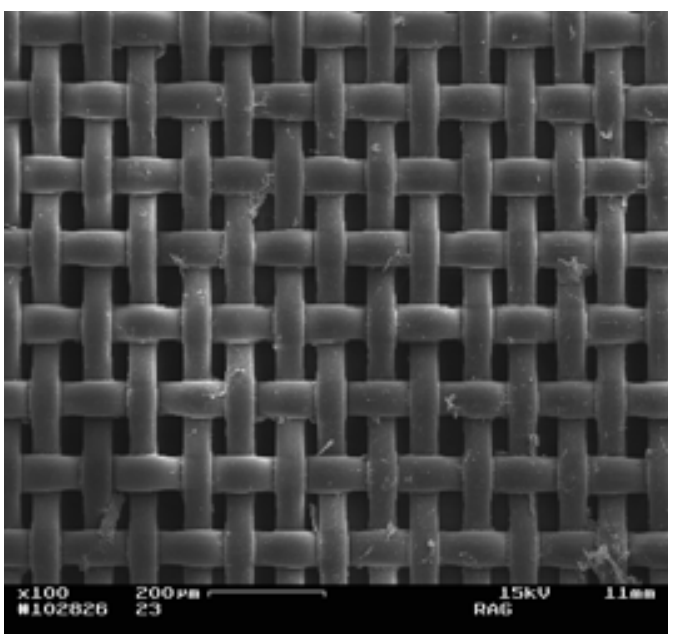

Figura 1 - Fotomicrografias eletrônicas de varredura do tecido náilon pré-incubação (a) (200x), pós-incubação (b) (100x) e pós-tratamento com detergente neutro (c) (100x).
Logo, associando-se os resultados obtidos por Huhtanen et al. (1994) aos obtidos neste estudo (Tabelas 2 e 4), infere-se que porosidades de 40 a $60 \mu \mathrm{m}$, embora recomendadas para estudos in situ (Nocek, 1997), não se mostraram apropriadas para avaliação dos teores de fibra insolúvel e resíduos fibrosos indigestíveis em ensaios com ruminantes.

De forma similar, as fotomicrografias eletrônicas dos tecidos F57 (Figura 2) e TNT (Figura 3), permitiram evidenciar, assim como no náilon, a preservação de sua integridade física pós-incubação (Figuras 2b e 3b) e póstratamento com detergente neutro (Figuras 2c e 3c) em comparação ao tecido pré-incubação (Figuras 2a e 3a).

Os tecidos F57 e TNT apresentam arranjo das malhas bastante semelhantes (Figuras 2 e 3 ) e a disposição das fibras sintéticas não permite evidenciar regularidade no arranjo geométrico como observado para o náilon (Figura 1).

Com base nos resultados demonstrados diretamente nas Tabelas 2 e 4 e, em análise comparativa ao comportamento verificado para o náilon, pode-se inferir que o arranjo das malhas dos tecidos F57 e TNT confere estruturas que permitem o influxo de microrganismos para degradar o alimento e, ao mesmo tempo, limitam a saída de partículas fibrosas não-degradadas.

Por outro lado, a redução do tamanho dos poros do tecido pode comprometer a retirada de gases oriundos da fermentação, limitando a acessibilidade microbiana e, conseqüentemente, reduzindo a degradação da FDN (Udén et al., 1974). Desta forma, mesmo não apresentando arranjo geométrico definido, os tecidos F57 e TNT (Figuras 2 e 3) apresentam aberturas inferiores às do náilon (Figura 1). Desta forma, o acúmulo de gases poderia também justificar as maiores estimativas de FDNi obtidas (Tabela 2).

Contudo, Lindberg \& Knutsson (1981), citados por Udén \& Van Soest (1984), ao avaliarem o desaparecimento de partículas em procedimento de incubação in situ utilizando sacos com diferentes porosidades (5, 10 e $20 \mu \mathrm{m})$, verificaram menores resíduos fibrosos para a menor porosidade nos tempos iniciais de incubação. Contudo, após 24 horas de incubação, as curvas de degradação tenderam a convergir, de modo que os resíduos foram considerados idênticos para todas as porosidades após 72 horas.

Neste contexto, o acúmulo de gases no interior dos sacos parece não interferir nas estimativas de resíduos indegradáveis, uma vez que tempos elevados de incubação são utilizados. Assim, a soma destes fatores mais uma vez comprova a perda de partículas propiciada pelo náilon como o principal fator de interferência sobre a exatidão das estimativas de FDNi. 
(a)

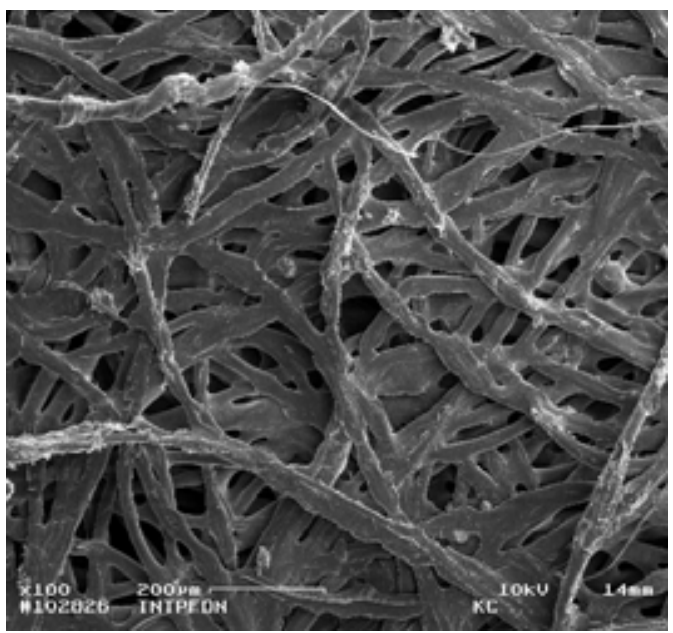

(b)

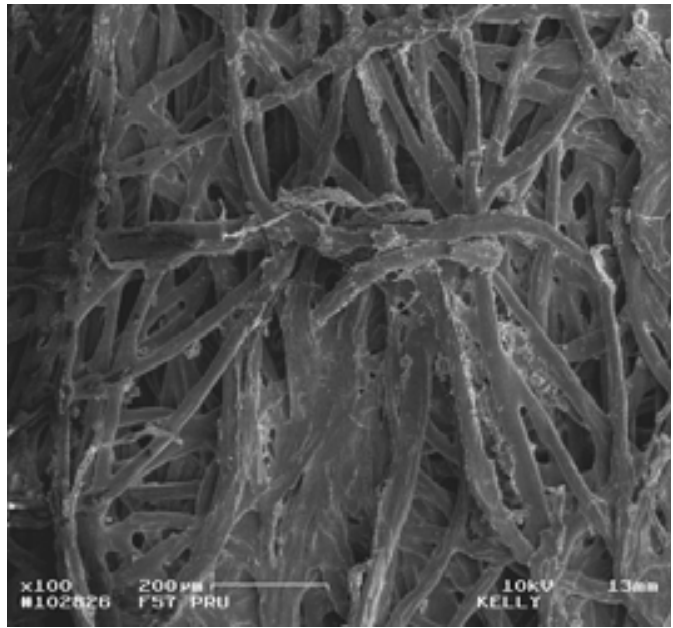

(c)

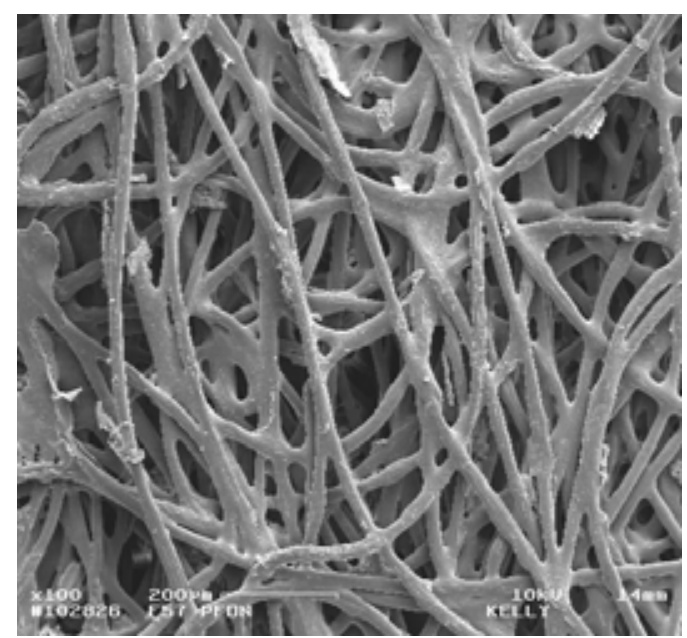

Figura 2 - Fotomicrografias eletrônicas de varredura do tecido F57 pré-incubação (a) (100x), pós-incubação (b) (100x) e pós-tratamento com detergente neutro (c) (100x). (a)

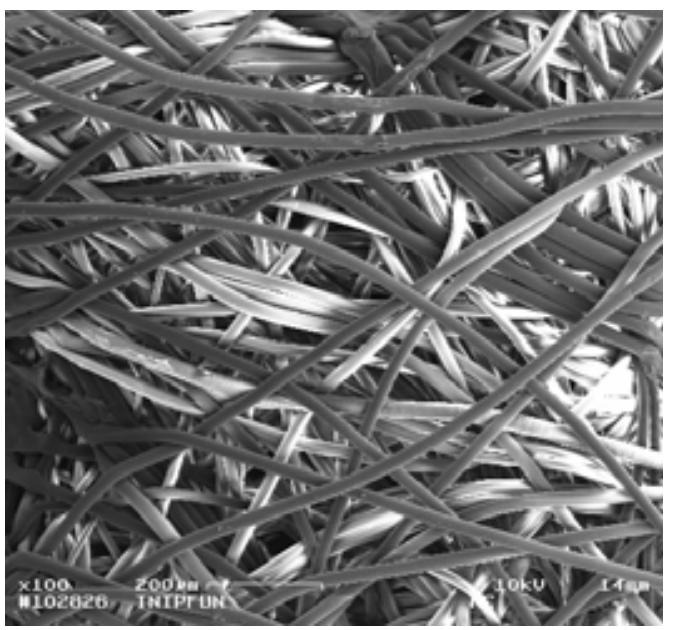

(b)

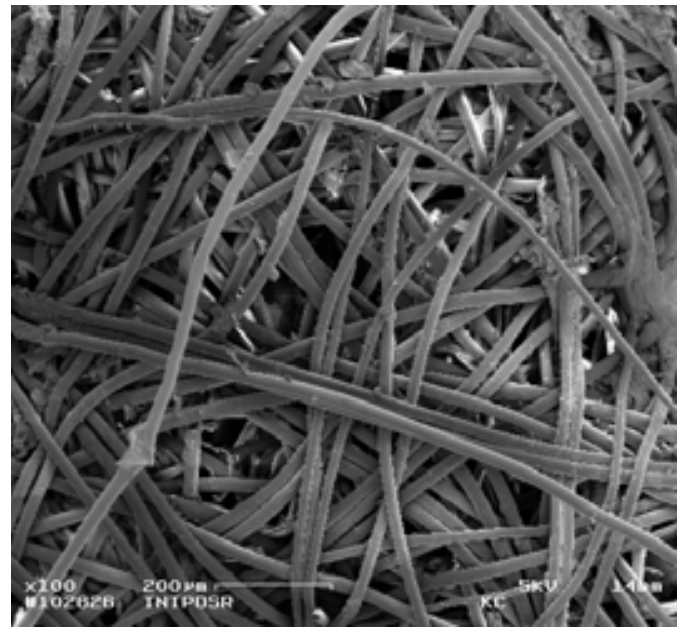

(c)

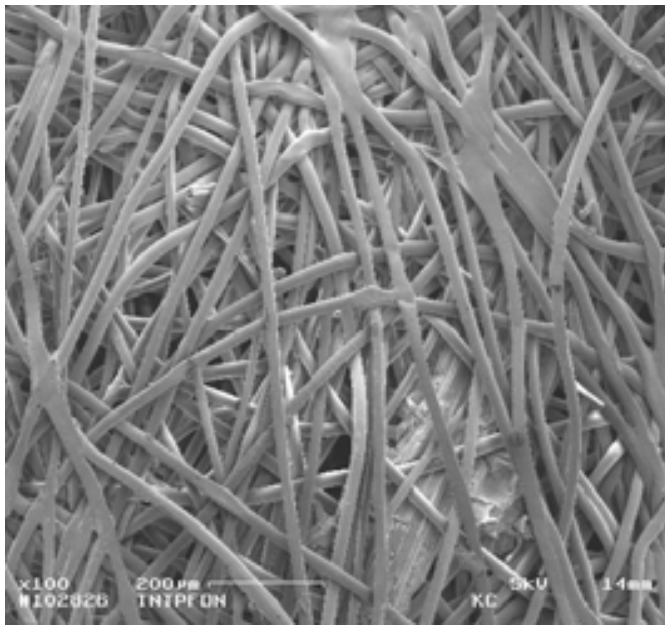

Figura 3 - Fotomicrografias eletrônicas de varredura do tecido não-tecido pré-incubação (a) (100x), pós-incubação (b) (100x) e pós-tratamento com detergente neutro (c) (100x). 
Em alguns estudos com indicadores internos em ruminantes, tem-se sugerido a utilização da MS indigestível (MSi) como indicador (Huhtanen et al., 1994; Detmann et al., 2001), a qual apresentaria menor custo analítico em comparação a resíduos de fibra indigestível (Detmann et al., 2001). Contudo, segundo Huhtanen et al. (1994), embora a MSi possa produzir resultados exatos, a presença de contaminantes pode comprometer os resultados obtidos. De fato, verificou-se a presença de contaminantes aderidos à malha dos tecidos pós-incubação, mesmo após a lavagem até o total clareamento da água (Figuras 1b, 2b e 3b). A presença destes contaminantes foi mais evidente no náilon (Figura 1b) e indica que cautela deve ser tomada na aplicação da MSi como indicador interno.

Por outro lado, embora com estrutura de malha similar à do F57, a superfície do TNT não apresenta poros em sua totalidade, uma vez que parte da superfície é vedada por calor durante o processo de fabricação do tecido (Figura 4).

Essa estrutura do tecido fez com que no TNT a relação entre MS incubada e superfície porosa fosse superior à recomendada por Nocek (1997), o que, em tese, poderia comprometer a acessibilidade microbiana ou o efluxo de material solúvel, ampliando as estimativas de FDNi e FDN. Contudo, na comparação entre TNT e F57 (Tabelas 2 e 4) esse fato não foi verificado. No entanto, com o intuito de se obterem padrões para os procedimentos in situ, sugerem-se mais estudos para quantificação exata da superfície efetivamente disponível à passagem microbiana e à saída de produtos da degradação com o uso do TNT.

De forma geral, os tecidos F57 e TNT apresentaram comportamento similar em termos analíticos. No entanto, apesar da similaridade física verificada entre estes tecidos (Figuras 2, 3 e 4), as pequenas divergências observadas nos teores de FDN e FDNi (Tabelas 2 e 4 ) permitem sugerir que cautela ainda deve ser observada para que se generalize o uso do TNT em procedimentos in situ. Neste contexto, mais estudos são necessários para averiguação das causas destas divergências.

Caso a similaridade analítica entre o F57 e o TNT seja confirmada, a avaliação de características secundárias dos procedimentos in situ permite apontar prerrogativa ao TNT, em virtude de seu menor custo (US\$ 0,01/saco) em comparação ao F57 (US\$ 2,00/saco).

\section{Conclusões}

A utilização do tecido F57 (Ankom ${ }^{\circledR}$ ) é recomendada para obtenção dos teores de fibra em detergente neutro indigestível pela técnica in situ em função da exatidão (a)

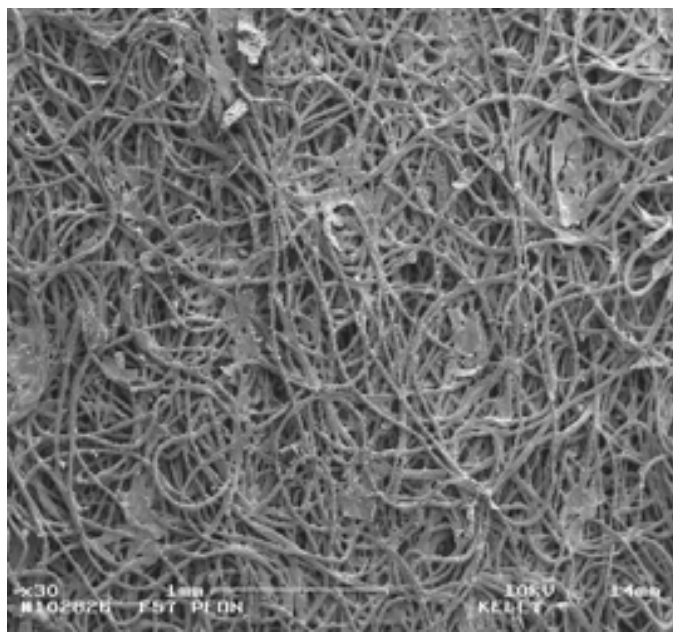

(b)

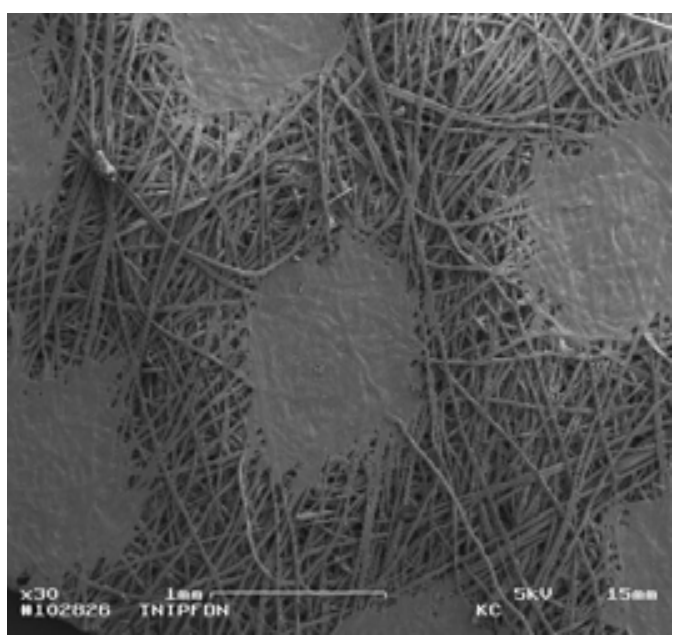

Figura 4 - Fotomicrografias eletrônicas de varredura dos tecidos F57 (a) (30x) e TNT (b) (30x) pós-tratamento com detergente neutro.

das estimativas obtidas. O tecido não-tecido $\left(100 \mathrm{~g} / \mathrm{m}^{2}\right)$ pode constituir alternativa de menor custo ao F57 em estudos para quantificação de compostos fibrosos indigestíveis em alimentos, uma vez que apresenta, em geral, estimativas com níveis similares de exatidão e precisão. Contudo, em virtude de pequenas divergências observadas neste estudo, sugerem-se novas avaliações do tecido não-tecido para que sua recomendação possa ser realizada de forma generalizada. A utilização do náilon em procedimentos similares, embora resulte em maior precisão, conduz a estimativas não-exatas, em decorrência da perda significativa de partículas fibrosas insolúveis. 


\section{Literatura Citada}

BERCHIELLI, T.T.; SADER, A.P.O.; TONANI, F.L. et al. Avaliação da determinação da fibra em detergente neutro e da fibra em detergente ácido pelo sistema ANKOM. Revista Brasileira de Zootecnia, v.30, p.1572-1578, 2001.

DETMANN, E.; PAULINO, M.F.; ZERVOUDAKIS, J.T. et al. Cromo e indicadores internos na determinação do consume de novilhos mestiços, suplementados, a pasto. Revista Brasileira de Zootecnia, v.30, p.1600-1609, 2001.

DETMANN, E.; VALADARES FILHO, S.C.; PAULINO, M.F. et al. Avaliação da técnica dos indicadores na estimação do consumo por ruminantes em pastejo. Caderno Técnico de Veterinária e Zootecnia, n.45, p.40-57, 2004.

FREITAS, D.; BERCHIELLI, T.T.; SILVEIRA, R.N. et al. Produção fecal e fluxo duodenal de matéria seca e matéria orgânica estimados através de indicadores. Revista Brasileira de Zootecnia, v.31, p.1521-1530, 2002.

HUHTANEN, P.; KAUSTELL, K.; JAAKKOLA, S. The use of internal markes to predict total digestibility and duodenal flow of nutrients in cattle given six different diets. Animal Feed Science and Technology, v.48, p.211-227, 1994.

HVELPLUND, T.; WEISBJERG, M.R. In situ techniques for the estimation of protein degradability and postrumen availability In: GIVENS, D.I.; OWEN, E.; AXFORD, R.F.E. et al. (Eds) Forage evaluation in ruminant nutrition. London: $\mathrm{CAB}$ International, 2000. p.233-258.

LITTELL, R.C.; FREUND, R.J.; SPECTOR, P.C. SAS System for linear models. 3.ed. Cary: SAS Institute, 1991. 329p.

MERTENS, D.R. Gravimetric determination of amylase-treated neutral detergent fiber in feeds with refluxing in beaker or crucibles: collaborative study. Journal of AOAC International, v.85, p.1217-1240, 2002.
NOCEK, J.E. In situ and other methods to estimate ruminal protein and energy digestibility: a review. In: TEIXEIRA, J.C. (Ed.) Digestibilidade em ruminantes. Lavras: FAEPE, 1997. p.197-240.

NUNES, C.J.; VELASQUEZ, P.A.T.; CARRILHO, E.N.V.M. et al. Material alternativo para confecção de filtros empregados na metodologia "nylon bag" para a determinação de fibra. In: REUNIÃO ANUAL DA SOCIEDADE BRASILEIRA DE ZOOTECNIA, 42., 2005, Goiânia: Sociedade Brasileira de Zootecnia, 2005. (CD-ROM).

PIAGGIO, L.M.; PRATES, E.R.; PIRES, F.F. et al. Avaliação das cinzas insolúveis em ácido, fibra detergente ácido indigestível e lignina em detergente ácido indigestível como indicadores internos da digestibilidade. Revista da Sociedade Brasileira de Zootecnia, v.20, p.306-312, 1991.

SILVA, D.J.; QUEIROZ, A.C. Análise de alimentos: métodos químicos e biológicos. 3.ed. Viçosa, MG: Editora UFV, 2002. 235p.

SILVEIRA, M. Preparo de amostras biológicas para microscopia eletrônica de varredura. In: SOUZA, W. (Ed.) Técnicas básicas de microscopia eletrônica aplicadas às ciências biológicas. Rio de Janeiro: Sociedade Brasileira de Microscopia Eletrônica, 1998. p.33-44.

SteEl, R.G.; TORRIE, J.H.; DICKEy, D.A. Principles and procedures of statistics. A biometrical approach. New York: McGraw-Hill Co., 1997. 666p.

UDÉN, P.; PARRA, R.; Van SOEST, P.J. Factors influencing reliability of the nylon bag technique. Journal of Dairy Science, v.57, p.622-622, 1974.

UDÉN, P.; Van SOEST, P.J. Investigation of the in situ bag technique and a comparison of the fermentation in heifers, sheep, ponies and rabbits. Journal of Animal Science, v.58, p.213-221, 1984.

Van SOEST, P.J. Nutritional ecology of the ruminant. 2.ed. Ithaca: Cornell University Press, 1994. 476p. 